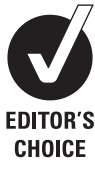

Additional data (supplementary tables and figures) are published online only. To view these files, please visit the journal online (http://ard.bmj.com/ content/71/6.toc).

${ }^{1}$ Department of Rheumatology, Leiden University Medical Centre, Leiden, The Netherlands 2Department of Rheumatology and Clinical Immunology, University of Hong Kong, Hong Kong, China

${ }^{3}$ Department of Rheumatology, Coimbra University Hospital, Coimbra, Portugal

${ }^{4}$ Department of Rheumatology, Ambroise Paré Hospital, Boulogne-Billancourt, France ${ }^{5}$ Rheumatology B Department, APHP, Cochin Hospital, Paris-Descartes University, Paris, France

\section{Correspondence to}

Professor Maxime Dougados, Rheumatology B Department, Cochin Hospital, Paris 75014, France;

m.doug@cch.aphp.fr

Accepted 10 September 2011 Published Online First 11 October 2011

\title{
Smokers in early axial spondyloarthritis have earlier disease onset, more disease activity, inflammation and damage, and poorer function and health-related quality of life: results from the DESIR cohort
}

\author{
Ho Yin Chung, ${ }^{1,2}$ Pedro Machado, ${ }^{1,3}$ Désirée van der Heijde, ${ }^{1}$ Maria-Antonietta D'Agostino, ${ }^{4}$ \\ Maxime Dougados ${ }^{5}$
}

\begin{abstract}
Objectives To investigate the association of smoking with various clinical, functional and imaging outcomes in patients with early axial spondyloarthritis (SpA).

Methods 647 patients with early inflammatory back pain (IBP) fulfilling at least one of the internationally accepted SpA criteria and with available smoking data were included in the analyses. Clinical, demographic and imaging parameters were compared between smokers and non-smokers at a cross-sectional level. Variables with significant differences in univariate analyses were used as dependent variables in multivariate linear and logistic regression models adjusted for potential confounding/contributing factors.
\end{abstract}

Results Multivariate analysis showed that smoking was associated with an earlier onset of IBP (regression coefficient $(B)=(-1.46), p=0.04)$, higher disease activity (ankylosing spondylitis disease activity score $B=0.20, p=0.03$; Bath ankylosing spondylitis disease activity index $B=0.50, p=0.003$ ), worse functional status (Bath ankylosing spondylitis functional index $B=0.38, p=0.02)$, more frequent $M R I$ inflammation of the sacroiliac joints (OR 1.57, $p=0.02$ ) and the spine (OR 2.33, $p<0.001)$, more frequent MRI structural lesions of the sacroiliac joints (OR 1.54, $p=0.03$ ) and the spine (OR 2.02, $p=0.01$ ), and higher modified Stoke ankylosing spondylitis spine score $(B=0.54, p=0.03)$ reflecting radiographic structural damage of the spine. Smoking was also associated with poorer quality of life (Euroquality of life questionnaire $B=1.38, p<0.001$, short form 36 physical $B=(-4.89), p<0.001$, and mental component score $B=(-5.90), p<0.001)$.

Conclusion In early axial SpA patients, smoking was independently associated with earlier onset of IBP, higher disease activity, increased axial inflammation on MRI, increased axial structural damage on MRI and radiographs, poorer functional status and poorer quality of life.

The interaction between genetic and environmental factors is important in rheumatic diseases, with rheumatoid arthritis (RA) being the classic example of this gene-environment interaction model. Smoking is the best established and most extensively studied environmental risk factor in RA since an association was first reported in the 80 's. ${ }^{1}$ Smoking in men, ${ }^{2}$ in the presence of anticitrullinated protein antibodies, ${ }^{3}$ and with the human leucocyte antigen (HLA)-DR shared epitope gene ${ }^{4}$ were each individually found to be risk factors for developing RA. Recent research has also shown additive and multiplicative interactions between PTPN22 and heavy smoking in RA. ${ }^{5}$

Fewer studies have been performed in ankylosing spondylitis (AS), and none in early axial spondyloarthritis (SpA). Smoking was found to be associated with increased disease activity, ${ }^{6}$ worse physical functioning ${ }^{6-10}$ and poorer quality of life, ${ }^{11}$ but inconsistently associated with radiographic severity $^{712}$ in established AS.

The newly developed Assessment of SpondyloArthritis International Society classification criteria for axial SpA ${ }^{13} 14$ are more inclusive of patients at an early disease stage. As smoking is a well-established risk factor for developing $\mathrm{RA}^{15-17}$ and other inflammatory diseases, such as systemic lupus erythematosus ${ }^{18}$ and inflammatory bowel disease, ${ }^{19}$ and has also been associated with phenotypic variations in AS, $6-1012$ it would be worthwhile to clarify the impact of smoking in the axial SpA spectrum, particularly in early stage SpA. The aim of our study was to determine the prevalence of smoking and its association with various clinical, functional and imaging outcomes in early axial SpA.

\section{METHODS}

This is a cross-sectional analysis involving data collected during the first visit of the Devenir des Spondylarthropathies Indifférenciées Récentes (DESIR) cohort, ${ }^{20}$ a large multicentre sample consisting of 708 patients in France. Only patients fulfilling at least one of the following classification criteria for axial SpA or AS were included in the analyses: the modified New York criteria, ${ }^{21}$ European Spondyloarthropathy Study Group criteria, ${ }^{22}$ Amor criteria, ${ }^{23}$ or Assessment of SpondyloArthritis International Society classification criteria for axial SpA. Details about the cohort design and data collection were described in previous publications. ${ }^{20} 24$ In this study, we investigated the influence of smoking on the outcome measures described below. In DESIR, smoking status was obtained through interview by the physician, without a standardised questionnaire. It was collected as past history or concomitant smoking, without any reference to the quantity (eg, pack-years). The drinking status was captured in a similar way as the smoking status. 


\section{Disease activity, function, mobility and quality of life}

Disease activity was assessed using both the Bath ankylosing spondylitis disease activity index (BASDAI ${ }^{25}$ and the ankylosing spondylitis disease activity score (ASDAS). ${ }^{26}$ The ASDAS was calculated using C-reactive protein (ASDAS-CRP). The Ritchie articular index (53 joints) and swollen joint count (28 joints) were performed to evaluate the peripheral joints, and those with relevant symptoms were assessed for extra-articular features.

Patients also completed the Bath ankylosing spondylitis functional index (BASFI $)^{27}$ and the health assessment questionnaire for ankylosing spondylitis (HAQ-AS), ${ }^{28}$ to assess functional status. Higher scores represent increased disease activity (ASDAS and BASDAI) and poorer functional status (BASFI and $\mathrm{HAQ}-\mathrm{AS})$.

Mobility was measured by the degree of chest expansion and by the Bath ankylosing spondylitis metrology index (BASMI). ${ }^{29}$ A higher BASMI score represents worse spinal mobility.

Patients completed the Euro-quality of life questionnaire (Euro-QoL), ${ }^{30}$ and the short form 36 (SF-36) ${ }^{31}$ to assess healthrelated quality of life (HRQoL). A higher Euro-QoL score represents worse HRQoL, while a higher SF-36 score represents better HRQoL.

\section{Radiographs of the sacroiliac joints and the spine}

Radiographs of the cervical spine, lumbar spine and sacroiliac joints were performed. Sacroiliac joint radiographs were graded according to the following grading scale: 0 , normal; 1 , doubtful; 2, obvious; 3, fusion. Radiographic sacroiliitis was defined by at least a unilateral 'obvious' grading scale. The modified Stoke ankylosing spondylitis spine score (mSASSS) ${ }^{32}$ was calculated from the radiographs of the cervical and lumbar spine. All radiographs were graded by regional radiologists or rheumatologists.

\section{Inflammation and structural lesions in MRI}

MRI were performed to look for inflammatory and structural lesions. Similar to radiographs, they were evaluated by regional radiologists or rheumatologists. The MRI were classified as having definite, doubtful or absent inflammatory and/or structural lesions at the spinal and sacroiliac joint levels according to short $\tau$ inversion recovery and T1-weighted fast spin echo images, respectively (1-1.5 Tesla). Positive images in our analyses were defined as MRI with definite lesions.

\section{Statistical analyses}

The $\chi^{2}$ statistic and independent samples $t$ test were used to compare categorical and continuous variables between smokers and non-smokers. Variables noted to have differences (with a $p$ value $<0.1$ ) in the previous analyses were used as dependent variables in univariate and multivariate linear/logistic regression models.

In addition to smoking status, factors known or expected to be associated with the investigated dependent variables were also tested as regressors in linear/logistic univariate regression analyses. These included: Caucasian race, male sex, HLA-B27 positivity, family history of SpA, age of inflammatory back pain (IBP) onset, duration of IBP, drinking status, CRP, erythrocyte sedimentation rate (ESR), MRI sacroiliac joint inflammatory lesions, MRI spine inflammatory lesions, non-steroidal anti-inflammatory drug (NSAID) use, ASDAS-CRP and BASMI. Independent variables with a $p$ value less than 0.1 in univariate linear/logistic regression analyses were re-tested in multivariate regression models. Interactions between smoking status and gender/HLAB27 were tested in each model. Separate regression models were built according to gender/HLA-B27 status if such an interaction existed. Variables with a skewed distribution were transformed using natural logarithms in linear regression models (ESR and $\mathrm{CRP}$ ). The results were reported as $\mathrm{OR}$ in logistic regression models, and regression coefficients (B) and standard coefficients $(\beta)$ in linear regression models. The $95 \% \mathrm{CI}$ were calculated and $p$ values less than 0.05 were considered statistically significant. All statistical analyses were performed using the statistical product and service solutions package 18.0.

\section{RESULTS}

Six hundred and fifty-four patients $(92.4 \%$ of recruited patients) fulfilled at least one of the internationally accepted SpA criteria. Smoking data were missing in seven of 654 patients $(1.1 \%)$, resulting in 647 patients included in our analyses. Detailed characteristics of this study population have previously been reported. ${ }^{24}$ The number of smokers (past history or concomitant smoking) in the analysed sample was 241 (37.2\%).

Table 1 compares the baseline characteristics between smoking and non-smoking early SpA patients. Smokers were more likely to be men, had an earlier onset of IBP and higher disease activity (higher BASDAI and ASDAS-CRP). Functionally, smokers had poorer functional status (increased BASFI and HAQ-AS) and also had poorer HRQoL (increased Euro-QoL and decreased SF-36) and more missing workdays as a result of SpA. On imaging examinations, smokers were more likely to have MRI inflammation and structural damage as well as radiographic lesions in the spine and sacroiliac joints.

\section{Regression analyses}

\section{Age of IBP onset as dependent variable}

Independent variables tested in univariate analyses included: Caucasian race, male sex, HLA-B27 positivity, family history of $\mathrm{SpA}$, and smoking and drinking status. Significant variables associated with the age of onset of IBP $(p<0.1)$ were: Caucasian race $(B=2.5, p=0.03)$, male sex $(B=(-2.06), p=0.003)$, HLA-B27 positivity $(B=(-2.95), p<0.001)$, family history of $\mathrm{SpA}(B=1.58$, $\mathrm{p}=0.05)$ and smoking $(\mathrm{B}=(-1.46), \mathrm{p}=0.04)$.

Multivariate analysis showed that Caucasian race $(\beta=0.13$, $\mathrm{B}=3.79,95 \%$ CI 1.55 to $6.04, \mathrm{p}=0.001)$ was independently associated with later age of IBP onset while HLA-B27 positivity $(\beta=(-0.44), B=(-2.60), 95 \% \mathrm{CI}-4.03$ to $-1.18, \mathrm{p}=0.02)$, smoking $(\beta=(-0.08), B=(-1.46), 95 \% \mathrm{CI}-2.87$ to $-0.06, \mathrm{p}=0.04)$ and male $\operatorname{sex}(\beta=(-0.10), B=(-1.67), 95 \% \mathrm{CI}-3.06$ to $-0.29, \mathrm{p}=0.02)$ were independently associated with earlier age of IBP onset.

\section{ASDAS-CRP and BASDAI as dependent variables}

Independent variables tested in univariate models of ASDASCRP included: Caucasian race, male sex, HLA-B27 positivity, family history of SpA, smoking, drinking, MRI sacroiliac joint inflammatory lesions, MRI spine inflammatory lesions and NSAID use. Independent variables with a $p$ value less than 0.1 were: Caucasian race $(B=(-0.57), p<0.001)$, HLA-B27 positivity $(B=(-0.2), p=0.02)$, smoking $(B=0.17, p=0.051)$, drinking $(B=(-0.25), p=0.04)$ and MRI spine inflammatory lesions $(\mathrm{B}=0.21, \mathrm{p}=0.04)$.

Independent variables tested in univariate models of BASDAI included: Caucasian race, male sex, HLA-B27 positivity, family history of SpA, smoking, drinking, CRP, ESR, MRI sacroiliac joint inflammatory lesions, MRI spine inflammatory lesions and NSAID use. Independent variables with a $\mathrm{p}$ value less than 0.1 were: Caucasian race $(B=(-1.07), p<0.001)$, male sex $(B=(-0.63)$, 
Table 1 Baseline characteristics of the study population, according to smoking status

\begin{tabular}{|c|c|c|c|}
\hline & Smoker & Non-smoker & p Value \\
\hline Male sex (N=647) & $123(51.0 \%)$ & $174(42.9 \%)$ & 0.04 \\
\hline Mean age at onset of IBP (years) $(N=628)$ & $31.1 \pm 8.3$ & $32.6 \pm 9.0$ & 0.04 \\
\hline Mean duration of axial symptoms (years) $(\mathrm{N}=628)$ & $1.6 \pm 1.0$ & $1.5 \pm 0.9$ & 0.44 \\
\hline Mean age at onset of peripheral arthritis (years) $(N=359)$ & $31.3 \pm 8.8$ & $33.1 \pm 9.7$ & 0.08 \\
\hline Mean age at onset of enthesitis (years) $(N=324)$ & $31.6 \pm 8.5$ & $33.4 \pm 9.0$ & 0.08 \\
\hline Caucasian race $(\mathrm{N}=646)$ & $220(91.7 \%)$ & $360(88.7 \%)$ & 0.22 \\
\hline Drinker $(\mathrm{N}=644)$ & $55(23.1 \%)$ & $40(9.9 \%)$ & $<0.001$ \\
\hline Family history of ankylosing spondyloarthritis ( $N=640$ ) & $63(26.4 \%)$ & $106(26.4 \%)$ & 0.98 \\
\hline HLA-B27 positive ( $N=641)$ & $157(65.7 \%)$ & $244(60.7 \%)$ & 0.21 \\
\hline History of peripheral arthritis $(\mathrm{N}=645)$ & $137(57.3 \%)$ & $241(59.4 \%)$ & 0.61 \\
\hline Signs of peripheral arthritis $(N=386)$ & $46(32.9 \%)$ & $99(40.2 \%)$ & 0.15 \\
\hline History of enthesitis $(\mathrm{N}=647)$ & $125(51.9 \%)$ & $218(53.7 \%)$ & 0.65 \\
\hline NSAID user $(\mathrm{N}=647)$ & $271(66.7 \%)$ & $173(71.8 \%)$ & 0.18 \\
\hline Steroid user $(\mathrm{N}=647)$ & $53(13.1 \%)$ & $29(12.0 \%)$ & 0.71 \\
\hline DMARD user $(\mathrm{N}=648)$ & $40(9.9 \%)$ & $19(7.9 \%)$ & 0.40 \\
\hline Analgesics user $(\mathrm{N}=647)$ & $258(63.5 \%)$ & $152(63.1 \%)$ & 0.90 \\
\hline Mean CRP (mg/l) (N=626) & $8.0 \pm 13.7$ & $7.7 \pm 14.0$ & 0.78 \\
\hline Patients with elevated CRP ( $N=626$ ) & $106(27.0 \%)$ & $80(34.3 \%)$ & 0.051 \\
\hline Mean ESR $(\mathrm{mm} / \mathrm{h})(621)$ & $12.9 \pm 14.7$ & $14.8 \pm 16.6$ & 0.14 \\
\hline Patients with elevated ESR (N=618) & $79(20.5 \%)$ & $45(19.4 \%)$ & 0.75 \\
\hline Patients with elevated CRP or ESR & $131(34.4 \%)$ & $89(38.9 \%)$ & 0.26 \\
\hline Patients with extra-articular features ( $N=647$ ) & $116(28.6 \%)$ & $63(26.1 \%)$ & 0.50 \\
\hline BASDAI $(N=641)$ & $4.6 \pm 1.9$ & $4.3 \pm 2.1$ & 0.06 \\
\hline BASDAI $\geq 4(N=641)$ & $150(63.3 \%)$ & $238(58.9 \%)$ & 0.27 \\
\hline ASDAS-CRP $(\mathrm{N}=618)$ & $2.6 \pm 1.0$ & $2.4 \pm 1.1$ & 0.051 \\
\hline BASFI $(N=634)$ & $3.4 \pm 2.2$ & $2.8 \pm 2.3$ & 0.001 \\
\hline $\mathrm{BASFI} \geq 4(\mathrm{~N}=634)$ & $96(40.5 \%)$ & $121(30.5 \%)$ & 0.01 \\
\hline Intensity of axial pain in last 2 days (NRS) $(N=644)$ & $5.2 \pm 2.8$ & $4.7 \pm 2.7$ & 0.03 \\
\hline Intensity of peripheral joints pain in last 2 days (NRS) $(N=643$ ) & $3.3 \pm 2.8$ & $3.2 \pm 2.8$ & 0.76 \\
\hline Tender joint count (out of 53 joints) $(\mathrm{N}=647)$ & $5.0 \pm 9.5$ & $4.1 \pm 7.9$ & 0.22 \\
\hline Swollen joint count (out of 28 joints) ( $N=645$ ) & $0.2 \pm 1.0$ & $0.2 \pm 0.8$ & 0.56 \\
\hline BASMI $(N=616)$ & $1.6 \pm 1.2$ & $1.5 \pm 1.1$ & 0.12 \\
\hline Chest expansion $(\mathrm{cm})(\mathrm{N}=645)$ & $5.7 \pm 2.0$ & $5.7 \pm 2.2$ & 0.99 \\
\hline Euro-quality of life questionnaire $(\mathrm{N}=645)$ & $10.4 \pm 4.8$ & $8.7 \pm 5.0$ & $<0.001$ \\
\hline HAQ-AS - disability index $(\mathrm{N}=644)$ & $1.0 \pm 0.7$ & $0.9 \pm 0.7$ & 0.06 \\
\hline SF-36 mental health component score $(\mathrm{N}=642)$ & $46.2 \pm 20.2$ & $52.7 \pm 20.5$ & $<0.001$ \\
\hline SF-36 physical health component score $(N=642)$ & $35.6 \pm 15.8$ & $40.5 \pm 16.9$ & $<0.001$ \\
\hline Patients with MRI inflammatory lesions in sacroiliac joints $(\mathrm{N}=610)$ & $104(46.8 \%)$ & $123(31.7 \%)$ & $<0.001$ \\
\hline Patients with MRI inflammatory lesions in spine $(\mathrm{N}=605)$ & $72(32.9 \%)$ & $64(16.6 \%)$ & $<0.001$ \\
\hline Patients with MRI structural lesions in sacroiliac joints $(\mathrm{N}=610)$ & $78(35.1 \%)$ & $92(23.7 \%)$ & 0.002 \\
\hline Patients with MRI structural lesions in spine $(\mathrm{N}=601)$ & $28(12.8 \%)$ & $26(6.8 \%)$ & 0.01 \\
\hline Patients with MRI inflammation, spine or sacroiliac joints ( $N=608)$ & $125(56.6 \%)$ & $149(38.5 \%)$ & $<0.001$ \\
\hline Patients with MRI structural lesions, spine or sacroiliac joints ( $N=604$ ) & $88(40.2 \%)$ & $108(28.1 \%)$ & 0.002 \\
\hline mSASSS (N=623) & $1.4 \pm 3.3$ & $0.9 \pm 2.6$ & 0.09 \\
\hline Patients with mSASSS $>0(N=623)$ & $66(28.6 \%)$ & $92(23.5 \%)$ & 0.16 \\
\hline Patients with radiographic sacroiliitis $(\mathrm{N}=625)$ & $78(33.8 \%)$ & $103(26.1 \%)$ & 0.04 \\
\hline Missing workdays $(\mathrm{N}=555)$ & $45.6 \pm 79.6$ & $27.3 \pm 61.4$ & 0.003 \\
\hline
\end{tabular}

$\mathrm{p}<0.001)$, HLA-B27 positivity $(\mathrm{B}=(-0.75), \mathrm{p}<0.001)$, smoking $(\mathrm{B}=0.31, \mathrm{p}=0.06)$, drinking $(\mathrm{B}=(-0.59), \mathrm{p}=0.01), \mathrm{CRP}(\mathrm{B}=0.25$, $\mathrm{p}<0.001)$, ESR $(\mathrm{B}=0.46, \mathrm{p}<0.001)$ and MRI sacroiliac joint inflammatory lesions $(B=(-0.60), p<0.001)$.

The multivariate analyses for ASDAS-CRP and BASDAI are shown in table 2 . Smoking was independently associated with higher ASDAS-CRP and BASDAI scores.

\section{BASFI and HAQ-AS as dependent variables}

Independent variables tested in univariate models of BASFI and $\mathrm{HAQ}-\mathrm{AS}$ included: Caucasian race, male sex, HLA-B27 positivity, family history of SpA, duration of IBP, smoking, drinking,
MRI sacroiliac joint inflammatory lesions, MRI spine inflammatory lesions, NSAID use, ASDAS-CRP and BASMI.

Independent variables with a $p$ value less than 0.1 in the BASFI model were: Caucasian race $(B=(-0.68), p<0.001)$, male sex $(\mathrm{B}=(-0.57), \mathrm{p}=0.002)$, HLA-B27 positivity $(\mathrm{B}=(-0.66), \mathrm{p}<0.001)$, smoking $(B=0.61, p=0.001)$, drinking $(B=(-0.63), p=0.01), M R I$ sacroiliac joint inflammatory lesions $(B=(-0.39), p=0.04), M R I$ spine inflammatory lesions $(B=0.46, p=0.04)$, ASDAS-CRP $(B=1.30, p<0.001)$ and BASMI $(B=0.64, p<0.001)$.

Independent variables with a $\mathrm{p}$ value less than 0.1 in the $\mathrm{HAQ}-\mathrm{AS}$ model were: Caucasian race $(\mathrm{B}=(-0.27), \mathrm{p}=0.003)$, male sex $(B=(-0.37), p<0.001)$, HLA-B27 positivity $(B=(-0.23)$, 


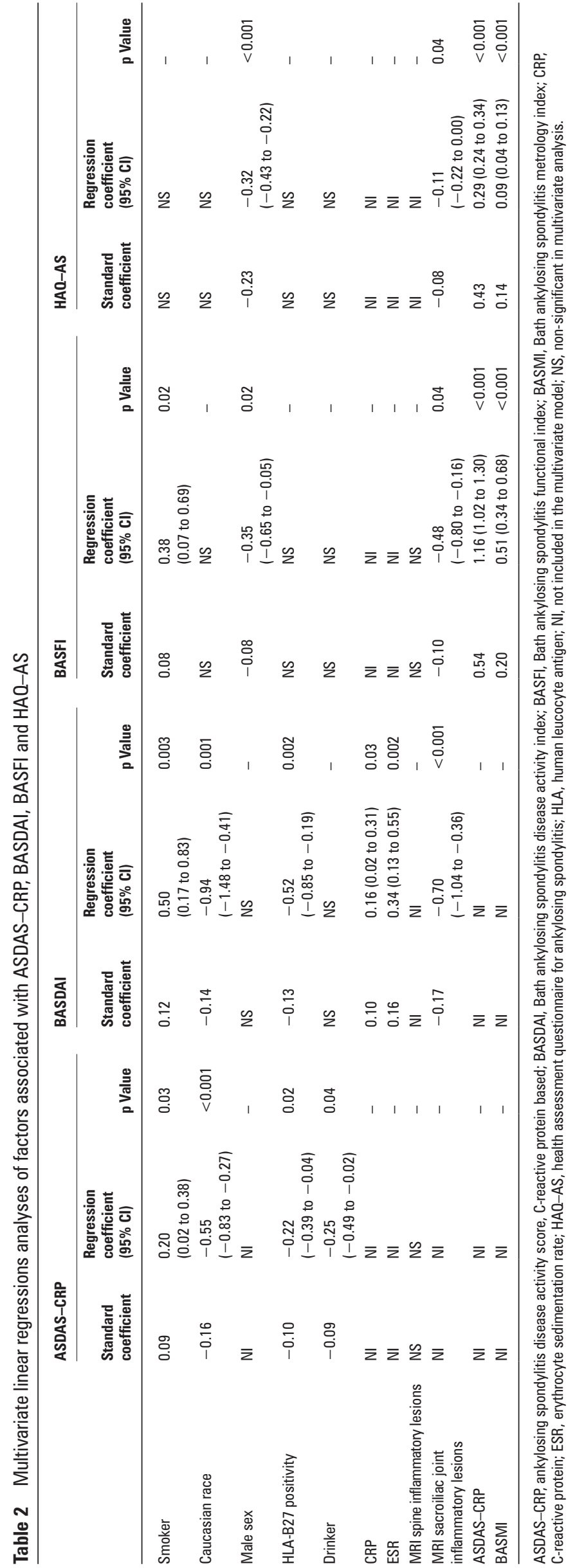

$\mathrm{p}<0.001)$, smoking $(\mathrm{B}=0.11, \mathrm{p}=0.06)$, drinking $(\mathrm{B}=(-0.16)$, $p=0.06)$, ASDAS-CRP $(B=0.33, p<0.001)$, MRI sacroiliac joint inflammatory lesions $(B=(-0.15), p=0.02)$ and $B A S M I(B=0.16$, $\mathrm{p}<0.001)$.

The multivariate analyses of BASFI and HAQ-AS are shown in table 2. Smoking was independently associated with higher BASFI scores. The univariate association between smoking and $\mathrm{HAQ}-\mathrm{AS}$ was lost in multivariate analysis.

\section{Euro-QoL and SF-36 as dependent variables}

Independent variables tested in univariate models of EuroQoL and SF-36 physical/mental component scores included: Caucasian race, male sex, HLA-B27 positivity, family history of SpA, duration of IBP, smoking, drinking, ASDAS-CRP, MRI sacroiliac joint inflammatory lesions, MRI spine inflammatory lesions and BASMI.

Independent variables in the Euro-QoL univariate models with a $p$ value less than 0.1 were: Caucasian race $(B=(-2.44)$, $\mathrm{p}<0.001)$, male sex $(B=(-2.02), p<0.001)$, HLA-B27 positivity $(B=(-1.67), p<0.001)$, smoking $(B=1.67, p<0.001)$, drinking $(B=(-1.27), p=0.02)$, ASDAS-CRP $(B=2.75, p<0.001)$, MRI sacroiliac joint inflammatory lesions $(B=(-1.39), p=0.001)$ and $B A S M I$ $(\mathrm{B}=1.10, \mathrm{p}<0.001)$.

Independent variables in the SF-36 physical component univariate models with a $p$ value less than 0.1 were: Caucasian race $(B=9.79, p<0.001)$, male sex $(B=5.65, p<0.001)$, HLA-B27 positivity $(B=5.18, p<0.001)$, smoking $(B=(-4.93), p<0.001)$, drinking $(\mathrm{B}=4.02, \mathrm{p}=0.03)$, ASDAS-CRP $(\mathrm{B}=(-9.19), \mathrm{p}<0.001)$, MRI sacroiliac joint inflammatory lesions $(B=4.81, p=0.001)$ and $B A S M I$ $(\mathrm{B}=(-3.57), \mathrm{p}<0.001)$.

Independent variables in the SF-36 mental component univariate models with a $p$ value less than 0.1 were: Caucasian race $(B=12.2, p<0.001)$, male sex $(B=5.68, p<0.001)$, HLA-B27 positivity $(B=5.02, p=0.03)$, smoking $(B=(-6.51), p<0.001)$, drinking $(B=5.29, p=0.02)$, ASDAS-CRP $(B=(-10.14), p<0.001)$, MRI sacroiliac joint inflammatory lesions $(B=4.89, p=0.01)$ and $B A S M I$ $(\mathrm{B}=3.13, \mathrm{p}<0.001)$.

Table 3 shows the multivariate analyses for Euro-QoL and SF-36. Smoking was independently and positively associated with the Euro-QoL score and negatively associated with the SF-36 physical and mental component scores.

MRI spine and/or sacroiliac joint inflammation, MRI spine inflammation and MRI sacroiliac joint inflammation as dependent variables

Independent variables tested in univariate models of the above three dependent variables included: Caucasian race, male sex, HLA-B27 positivity, family history of SpA, age at onset of IBP, duration of IBP, CRP, smoking, drinking and NSAID use.

Independent variables in MRI spine and/or sacroiliac joint inflammation models with $\mathrm{p}$ value less than 0.1 were: male sex (OR 2.32, $\mathrm{p}<0.001$ ), HLA-B27 positivity (OR 2.33, $\mathrm{p}<0.001$ ), age at onset of IBP (OR 0.97, $\mathrm{p}=0.001)$, CRP (OR 1.02, $\mathrm{p}=0.001)$ and smoking (OR 2.08, p<0.001).

Independent variables in MRI spine inflammation models with a $\mathrm{p}$ value less than 0.1 were: male sex $(\mathrm{OR} 2.47, \mathrm{p}<0.001)$, HLA-B27 positivity (OR 1.73, $\mathrm{p}=0.01$ ), family history of SpA (OR 1.68, $\mathrm{p}=0.03$ ), $\mathrm{CRP}(\mathrm{OR} 1.02, \mathrm{p}=0.03$ ) and smoking (OR $2.46, \mathrm{p}<0.001)$.

Independent variables in MRI sacroiliac joint inflammation models with a $\mathrm{p}$ value less than 0.1 were: Caucasian race (OR $0.59, \mathrm{p}=0.05)$, male sex (OR 2.37, $\mathrm{p}<0.001)$, HLA-B27 positivity (OR 2.38, $\mathrm{p}<0.001$ ), age at onset of IBP (OR 0.96, $\mathrm{p}<0.001)$, CRP $(\mathrm{OR} 1.02, \mathrm{p}=0.002)$, smoking (OR 1.90, $\mathrm{p}<0.001)$ and drinking (OR 1.52, p=0.07). 
Table 3 Multivariate linear regressions analyses of factors associated with Euro-QoL and SF-36

\begin{tabular}{|c|c|c|c|c|c|c|c|c|c|}
\hline & \multicolumn{3}{|l|}{ Euro-0oL } & \multicolumn{3}{|c|}{ SF-36 (physical health score) } & \multicolumn{3}{|c|}{ SF-36 (mental health score) } \\
\hline & $\begin{array}{l}\text { Standard } \\
\text { coefficient }\end{array}$ & $\begin{array}{l}\text { Regression } \\
\text { coefficient } \\
\text { (95\% Cl) }\end{array}$ & p Value & $\begin{array}{l}\text { Standard } \\
\text { coefficient }\end{array}$ & $\begin{array}{l}\text { Regression } \\
\text { coefficient } \\
\text { (95\% CI) }\end{array}$ & p Value & $\begin{array}{l}\text { Standard } \\
\text { coefficient }\end{array}$ & $\begin{array}{l}\text { Regression } \\
\text { coefficient } \\
\text { (95\% Cl) }\end{array}$ & p Value \\
\hline Caucasian race & NS & NS & - & 0.11 & $\begin{array}{l}6.09 \\
(2.21 \text { to } 9.98)\end{array}$ & 0.002 & 0.12 & $\begin{array}{l}8.17 \\
\text { (3.01 to } 13.31)\end{array}$ & 0.002 \\
\hline HLA-B27 positivity & NS & NS & - & NS & NS & - & NS & NS & - \\
\hline Drinker & NS & NS & - & NS & NS & - & NS & NS & - \\
\hline ASDAS-CRP & 0.52 & $\begin{array}{l}2.47 \\
(2.15 \text { to } 2.80)\end{array}$ & $<0.001$ & -0.52 & $\begin{array}{l}-8.32 \\
(-9.41 \text { to }-7.21)\end{array}$ & $<0.001$ & -0.46 & $\begin{array}{l}-9.08 \\
(-10.52 \text { to }-7.63)\end{array}$ & $<0.001$ \\
\hline $\begin{array}{l}\text { MRI sacroiliac joint } \\
\text { inflammation }\end{array}$ & -0.12 & $\begin{array}{l}-1.26 \\
(-1.96 \text { to }-0.56)\end{array}$ & $<0.001$ & 0.14 & $\begin{array}{l}4.94 \\
(2.56 \text { to } 7.32)\end{array}$ & $<0.001$ & 0.13 & $\begin{array}{l}5.33 \\
(2.20 \text { to } 8.46)\end{array}$ & 0.001 \\
\hline BASMI & 0.12 & $\begin{array}{l}0.56 \\
(0.26 \text { to } 0.86)\end{array}$ & $<0.001$ & -0.09 & $\begin{array}{l}-1.42 \\
(-2.45 \text { to }-0.39)\end{array}$ & 0.01 & NS & NS & - \\
\hline
\end{tabular}

ASDAS-CRP, ankylosing spondylitis disease activity score, C-reactive protein based; BASMI, Bath ankylosing spondylitis metrology index; Euro-0oL, Euro-quality of life questionnaire; HLA, human leucocyte antigen; NI, not included in the multivariate model; NS, non-significant in multivariate analysis; SF-36, short form 36.

Table 4 Multivariate logistic regressions analyses of factors associated with MRI inflammation

\begin{tabular}{|c|c|c|c|c|c|c|}
\hline & \multicolumn{2}{|c|}{$\begin{array}{l}\text { MRI inflammation } \\
\text { (spine or sacroiliac joints) }\end{array}$} & \multicolumn{2}{|c|}{ MRI sacroiliac joint inflammation } & \multicolumn{2}{|c|}{ MRI spine inflammation } \\
\hline & OR $(95 \% \mathrm{Cl})$ & p Value & OR (95\% Cl) & p Value & OR (95\% CI) & p Value \\
\hline Smoker & 1.91 (1.34 to 2.72$)$ & $<0.001$ & 1.57 (1.08 to 2.30$)$ & 0.02 & $2.33(1.55$ to 3.51$)$ & $<0.001$ \\
\hline Caucasian race & $\mathrm{NI}$ & - & $0.49(0.27$ to 0.87$)$ & 0.02 & $\mathrm{NI}$ & - \\
\hline Male sex & $1.87(1.31$ to 2.64$)$ & $<0.001$ & $1.80(1.24$ to 2.62$)$ & 0.002 & $1.98(1.30$ to 3.01$)$ & 0.001 \\
\hline HLA-B27 positivity & 2.06 (1.43 to 2.97$)$ & $<0.001$ & $2.08(1.40$ to 3.10$)$ & $<0.001$ & NS & - \\
\hline Drinker & $\mathrm{NI}$ & - & NS & - & $\mathrm{NI}$ & - \\
\hline Family history of SpA & $\mathrm{NI}$ & - & $\mathrm{NI}$ & - & NS & - \\
\hline Age at onset of IBP & NS & - & $0.97(0.95$ to 0.99$)$ & 0.01 & $\mathrm{NI}$ & - \\
\hline CRP & $1.02(1.01$ to 1.03$)$ & 0.01 & NS & - & $1.02(1.00$ to 1.03$)$ & 0.02 \\
\hline
\end{tabular}

CRP, C-reactive protein; HLA, human leucocyte antigen; IBP, inflammatory back pain; NI, not included in the multivariate model; NS, non-significant in multivariate analysis; SpA, spondyloarthritis.

In multivariate analyses, smoking was independently and positively associated with the presence of both sacroiliac joint and spine MRI inflammation (table 4).

\section{MRI spine and/or sacroiliac joint structural lesions, MRI spine structural lesions and MRI sacroiliac joint structural lesions as dependent variables}

Independent variables included in univariate models of the above three dependent variables included: Caucasian race, male sex, HLA-B27 positivity, family history of SpA, age at onset of IBP, disease duration, CRP, smoking, drinking and NSAID use.

Independent variables in MRI structural lesion models (spine and/or sacroiliac joints) with a p value less than 0.1 were: HLA-B27 positivity ( $O R$ 1.47, $p=0.04)$, duration of IBP ( $O R$ 1.19, $p=0.06$ ), CRP (OR 1.01, $\mathrm{p}=0.06$ ) and smoking (OR 1.72, $\mathrm{p}=0.02$ ).

Independent variables in MRI sacroiliac joint structural lesion models with a $\mathrm{p}$ value less than 0.1 were: HLA-B27 positivity (OR 1.67, $\mathrm{p}=0.01$ ), age at onset of IBP (OR 0.97, $\mathrm{p}=0.002)$, CRP (OR 1.01, $\mathrm{p}=0.04$ ) and smoking (OR 1.74, $\mathrm{p}=0.003$ ).

The only independent variable with a p value less than 0.1 in MRI spine structural lesion models was smoking (OR 2.02, $\mathrm{p}=0.01$ ).

The multivariate analyses of the above three dependent variables are shown in table 5 . Smoking was found to be positively associated with the presence of both sacroiliac joint and spine MRI structural lesions.

Smoking was found to interact with male sex regarding MRI sacroiliac joint structural lesions. Therefore, separate univariate and multivariate logistic regression models were performed according to gender. Variables with a $\mathrm{p}$ value less than 0.1 in the male population were: HLA-B27 positivity (OR 2.41, $\mathrm{p}=0.01$ ), age at onset of IBP (OR 0.97, $\mathrm{p}=0.09$ ) and smoking (OR 2.99, $\mathrm{p}<0.001)$. Multivariate analysis showed that smoking (OR 2.78, $\mathrm{p}<0.001)$ was positively associated with MRI sacroiliac joint structural lesions, while HLA-B27 positivity (OR 1.85, $\mathrm{p}=0.07)$ and age at onset of IBP (OR 0.98, p=0.23) were not significantly associated. Variables with a $\mathrm{p}$ value less than 0.1 in the female population were: Caucasian race $(\mathrm{OR} 0.63, \mathrm{p}=0.03)$ and age at onset of IBP (OR 0.97, $\mathrm{p}=0.02$ ); multivariate analysis showed that both Caucasian race (OR 0.48, $\mathrm{p}=0.046$ ) and age at onset of IBP (OR 0.97, $\mathrm{p}=0.03$ ) were associated with MRI sacroiliac joint structural lesions.

\section{Radiographic sacroiliitis and mSASSS as dependent variables}

Independent variables included in univariate models of the above two dependent variables included: Caucasian race, male sex, HLA-B27 positivity, family history of SpA, age at onset of IBP, duration of IBP, CRP, smoking, drinking and NSAID use.

Independent variables in radiographic sacroiliitis models with a $p$ value less than 0.1 were: male sex (OR 1.96, $p<0.001$ ), HLA-B27 positivity (OR 1.91, $p=0.001)$, age at onset of IBP (OR 0.96, p<0.001), CRP (OR 1.02, p<0.001), smoking (OR 1.44, $\mathrm{p}=0.04)$ and drinking (OR 1.77, $\mathrm{p}=0.02)$. Independent variables in mSASSS models with a $p$ value less than 0.1 were: male sex $(B=0.54, p=0.02)$, family history of $\operatorname{SpA}(B=(-0.58), p=0.03)$, age at onset of IBP $(B=0.06, p<0.001)$, CRP $(B=0.25, p=0.01)$ and smoking $(B=0.44, p=0.07)$. 
Table 5 Multivariate logistic regressions analyses of factors associated with MRI structural lesions

\begin{tabular}{|c|c|c|c|c|c|c|}
\hline & \multicolumn{2}{|c|}{$\begin{array}{l}\text { MRI structural lesions (sacroiliac } \\
\text { joints or spine) }\end{array}$} & \multicolumn{2}{|c|}{ MRI sacroiliac joint structural lesions } & \multicolumn{2}{|c|}{ MRI spine structural lesions } \\
\hline Smoker & 1.56 (1.08 to 2.26$)$ & 0.02 & 1.54 (1.05 to 2.26$)$ & 0.03 & 2.02 (1.15 to 3.55$)$ & 0.01 \\
\hline Age at onset of IBP & $\mathrm{NI}$ & - & $0.97(0.95$ to 1.00$)$ & 0.02 & $\mathrm{NI}$ & - \\
\hline CRP & NS & & NS & & $\mathrm{NI}$ & \\
\hline IBP duration & $1.26(0.03$ to 1.54$)$ & 0.02 & $\mathrm{NI}$ & - & $\mathrm{NI}$ & - \\
\hline
\end{tabular}

CRP, C-reactive protein; HLA, human leucocyte antigen; IBP, inflammatory back pain; NI, not included in the multivariate model; NS, non-significant in multivariate analysis.

Table 6 Multivariate linear/logistic regressions analyses of factors associated with radiographic sacroiliitis and mSASSS

\begin{tabular}{|c|c|c|c|c|c|}
\hline & \multicolumn{2}{|c|}{ Radiographic sacroiliitis } & \multicolumn{3}{|l|}{ mSASSS } \\
\hline & OR (95\% CI) & p Value & Standard coefficient & Regression coefficient $(95 \% \mathrm{CI})$ & p Value \\
\hline Smoker & NS & - & 0.09 & $0.54(0.05$ to 1.03$)$ & 0.03 \\
\hline HLA-B27 positivity & NS & - & $\mathrm{NI}$ & $\mathrm{NI}$ & - \\
\hline Male sex & $1.48(1.00$ to 2.18$)$ & 0.049 & 0.11 & $0.64(0.17$ to 1.12$)$ & 0.01 \\
\hline Family history of $\mathrm{SpA}$ & $\mathrm{NI}$ & - & -0.13 & $-0.91(-1.45$ to -0.37$)$ & 0.001 \\
\hline Age at onset of IBP & 0.97 (0.95 to 0.99$)$ & 0.004 & 0.23 & $0.08(0.05$ to 0.11$)$ & $<0.001$ \\
\hline CRP & $1.02(1.01$ to 1.03$)$ & 0.02 & 0.14 & $0.32(0.13$ to 0.51$)$ & 0.001 \\
\hline Drinker & NS & - & $\mathrm{NI}$ & $\mathrm{NI}$ & - \\
\hline
\end{tabular}

CRP, C-reactive protein; HLA, human leucocyte antigen; IBP, inflammatory back pain; mSASSS, modified Stoke ankylosing spondylitis spine score; NI, not included in the multivariate model; NS, non-significant in multivariate analysis; SpA, spondyloarthritis.

Multivariate models of radiographic sacroiliitis and mSASSS are shown in table 6. Smoking was found to be independently and positively associated with mSASSS but not with radiographic sacroiliitis.

\section{Interaction between smoking and HLA-B27 positivity}

There was no interaction between smoking and HLA-B27 positivity for any of the studied outcomes.

\section{Subgroup analysis}

Sacroiliac joint radiographic data were missing in 22/647 patients (3.4\%). Subgroup analyses were performed for patients fulfilling $(n=181)$ and not fulfilling $(n=444)$ the modified New York criteria (see supplements 1 and 2, available online only). In the subgroup of patients with radiographic axial SpA smoking was independently and positively associated with BASFI, Euro-QoL, MRI spinal inflammation, MRI spine or sacroiliac joint inflammation and radiographic damage of the spine. Smoking was also negatively associated with SF-36 (physical and mental component scores). In the subgroup of patients with non-radiographic axial SpA smoking was independently and positively associated with BASDAI, Euro-QoL and MRI spinal inflammation. It was negatively associated with age at onset of IBP and SF-36 (physical and mental component scores). Subgroup differences are likely due to loss of statistical power.

\section{DISCUSSION}

The negative impact of smoking on AS disease parameters has been reported in previous studies, and confirmed more robustly in our study. Importantly, we confirmed these associations in an early disease stage population with IBP of less than 3 years.

In addition to the negative impact of smoking on radiographic severity, clinical disease activity, functional status and quality of life, we have shown new associations: for the first time, smoking was found to be associated with the presence of MRI inflammation and structural damage. Radiographically, smoking was only associated with spinal, but not sacroiliac joint, damage (non-significant in multivariate analysis).
In the general population, smokers were found to have poorer HRQoL, increased alcohol consumption and increased frequency of reported pain. ${ }^{33}$ We studied drinking as a potential confounder in all our models and the effect of smoking was independent of drinking (and independent of other important variables such as NSAID intake). Drinking was only independently associated with ASDAS-CRP in multivariate analyses (negative association).

Previous studies have proposed that the negative impact of smoking on functional status and quality of life may be related to poor health behaviour, increased osteoporotic fractures and impaired cardiorespiratory functions in smokers. ${ }^{6} 910$ However, this negative impact might also be mediated by a direct toxic effect of smoking. Notably, cigarette smoke is well known to possess pro-inflammatory effects, via various proposed mechanisms: smokers have increased pro-inflammatory reactants such as tumour necrosis factor $\alpha$, interleukin (IL) 1, IL-6, IL-8 and granulocyte-macrophage colony-stimulating factor; ${ }^{34} 35$ increased concentration of free radicals; ${ }^{36}$ and augmentation of autoreactive B cells. ${ }^{37}$ Cigarette smoke triggers the nuclear factor $\kappa \mathrm{B}$ pathway and promotes pro-inflammatory cytokine gene expression. ${ }^{38}$ Moreover, smokers were also found to have increased circulating polymorphonuclear neutrophil counts ${ }^{39} 40$ and T lymphocytes. ${ }^{41}$

The DESIR cohort is characterised by SpA patients with short disease duration, in contrast with previous studies on AS patients with a longer course of disease. In this early SpA population (average duration of IBP only 1.5 years), smokers had an earlier age of IBP onset, which was not found in smaller studies. ${ }^{8}$ This demonstrates the enhanced power inherent in the large sample size of the DESIR cohort, allowing us to detect more subtle differences.

The cumulative effects of smoking in RA meta-analyses have established that male smokers are at increased risk but as the quantity of smoking increases, risk between male and female smokers becomes more equal. ${ }^{42}$ We found an interaction between male sex and smokers regarding MRI sacroiliac joint structural lesions. Given that the quantification of smoking affects the 
gender interaction in RA, it would be of interest to quantify the cumulative effect of cigarette smoking in future studies with SpA patients. Unfortunately, the number of pack-years of smoking is not known in the DESIR cohort. Furthermore, it would have been useful to analyse 'current smokers' and patients with a 'past history of smoking' separately-however, these data are also not known in DESIR.

The lack of international consensus about the assessment of MRI structural lesions poses another potential limitation to our study. However, in DESIR, the imaging techniques were standardised and the centres involved had to fulfil predefined quality criteria in order to be able to participate in the study, namely regarding previous experience with multicentre, longitudinal epidemiological studies. ${ }^{20}$ Therefore, the required high quality standards are expected to have reduced potential bias during the imaging evaluation.

Another concern is whether the physician interview-captured smoking status might have led to an under-reporting of smoking. However, the prevalence of smoking in DESIR is in line with the prevalence of smoking in the French ${ }^{43}$ population $(37.2 \%$ current smokers and ex-smokers in DESIR vs $26.2 \%$ current smokers in the French population). Furthermore, a previous study has shown that obtaining a history of tobacco use is an accurate method of detecting smokers in epidemiological studies. ${ }^{44}$

Our study found that, in young axial SpA patients with short disease duration, smoking was independently associated with earlier onset of IBP, higher disease activity, increased axial inflammation and structural damage, poorer functional status and poorer quality of life. This also translated into increased missing workdays as a result of disease (table 1), which may lead to a higher socioeconomic burden and costs, especially taking into account the relatively young age of onset and long expected disease survival of these patients. Taking into account that smoking is a potentially modifiable lifestyle factor, axial SpA patients who smoke should be strongly advised to quit this habit, as there seem to be disease-specific benefits that go beyond those described for the general population.

The DESIR cohort allowed us to establish the negative impact of smoking in axial SpA; continued follow-up of the cohort may allow detailed quantification of the deleterious impact of smoking at the individual and societal levels. The true magnitude and implications of this effect is yet to be unravelled.

Funding The DESIR study is conducted as a Programme Hospitalier de Recherche Clinique (PHRC) with Assistance Publique-Hôpitaux de Paris as the sponsor. The DESIR study is also under the umbrella of the French Society of Rheumatology, which is also financially supporting the cohort. An unrestricted grant from Pfizer has been allocated for the first 5 years. PM was supported by the Fundação para a Ciência e a Tecnologia (FCT) grant SFRH/BD/62329/2009.

\section{Competing interests None.}

\section{Patient consent Obtained.}

Ethics approval The DESIR study was approved by the French Departmental Directorate of Health and Social Affairs (Directeur Départemental des Affaires Sanitaires et Sociales) and has obtained the approval of the appropriate local ethics committees. It was conducted in accordance with the Declaration of Helsinki and the guidance for good clinical practice (French version), 30 November 2006.

Provenance and peer review Not commissioned; externally peer reviewed.

\section{REFERENCES}

1. Vessey MP, Villard-Mackintosh L, Yeates D. Oral contraceptives, cigarette smoking and other factors in relation to arthritis. Contraception 1987;35:457-64.

2. Heliövaara M, Aho K, Aromaa A, et al. Smoking and risk of rheumatoid arthritis. J Rheumatol 1993;20:1830-5.

3. Lee DM, Phillips R, Hagan EM, et al. Quantifying anti-cyclic citrullinated peptide titres: clinical utility and association with tobacco exposure in patients with rheumatoid arthritis. Ann Rheum Dis 2009;68:201-8.
4. van der Helm-van Mil AH, Wesoly JZ, Huizinga TW. Understanding the genetic contribution to rheumatoid arthritis. Curr Opin Rheumatol 2005;17:299-304.

5. Costenbader KH, Chang SC, De Vivo I, et al. Genetic polymorphisms in PTPN22, PADI-4, and CTLA-4 and risk for rheumatoid arthritis in two longitudinal cohort studies: evidence of gene-environment interactions with heavy cigarette smoking. Arthritis Res Ther 2008; 10:R52.

6. Kaan U, Ferda 0. Evaluation of clinical activity and functional impairment in smokers with ankylosing spondylitis. Rheumatol Int 2005;25:357-60.

7. Doran MF, Brophy S, MacKay K, et al. Predictors of longterm outcome in ankylosing spondylitis. J Rheumatol 2003;30:316-20.

8. Averns HL, Oxtoby J, Taylor HG, et al. Smoking and outcome in ankylosing spondylitis. Scand J Rheumatol 1996;25:138-42.

9. Ward MM, Weisman MH, Davis JC Jr, et al. Risk factors for functional limitations in patients with long-standing ankylosing spondylitis. Arthritis Rheum 2005; 53:710-17

10. Ward MM. Predictors of the progression of functional disability in patients with ankylosing spondylitis. J Rheumatol 2002;29:1420-5.

11. Bodur H, Ataman S, Rezvani A, et al. Quality of life and related variables in patients with ankylosing spondylitis. Qual Life Res 2011;20:543-9.

12. Ward MM, Hendrey MR, Malley JD, et al. Clinical and immunogenetic prognostic factors for radiographic severity in ankylosing spondylitis. Arthritis Rheum 2009;61:859-66.

13. Rudwaleit M, Landewé $\mathrm{R}$, van der Heiide $\mathrm{D}$, et al. The development of Assessment of SpondyloArthritis international Society classification criteria for axial spondyloarthritis (part I): classification of paper patients by expert opinion including uncertainty appraisal. Ann Rheum Dis 2009;68:770-6.

14. Rudwaleit M, van der Heijde D, Landewé R, et al. The development of Assessment of SpondyloArthritis international Society classification criteria for axial spondyloarthritis (part II): validation and final selection. Ann Rheum Dis 2009;68:777-83.

15. Bang SY, Lee KH, Cho SK, et al. Smoking increases rheumatoid arthritis susceptibility in individuals carrying the HLA-DRB1 shared epitope, regardless of rheumatoid factor or anti-cyclic citrullinated peptide antibody status. Arthritis Rheum 2010;62:369-77.

16. Carlens C, Hergens MP, Grunewald J, et al. Smoking, use of moist snuff, and risk of chronic inflammatory diseases. Am J Respir Crit Care Med 2010;181:1217-22.

17. Stolt $\mathbf{P}$, Bengtsson C, Nordmark B, et al. Quantification of the influence of cigarette smoking on rheumatoid arthritis: results from a population based case-control study, using incident cases. Ann Rheum Dis 2003;62:835-41.

18. Costenbader KH, Kim DJ, Peerzada J, et al. Cigarette smoking and the risk of systemic lupus erythematosus: a meta-analysis. Arthritis Rheum 2004;50:849-57.

19. Gearry RB, Richardson AK, Frampton CM, et al. Population-based cases control study of inflammatory bowel disease risk factors. J Gastroenterol Hepatol 2010;25:325-33.

20. Dougados M, d'Agostino MA, Benessiano J, et al. The DESIR cohort: a 10-year follow-up of early inflammatory back pain in France: study design and baseline characteristics of the 708 recruited patients. Joint Bone Spine 2011;Mar 30 (epub ahead of print).

21. van der Linden S, Valkenburg HA, Cats A. Evaluation of diagnostic criteria for ankylosing spondylitis. A proposal for modification of the New York criteria. Arthritis Rheum 1984:27:361-8.

22. Dougados M, van der Linden S, Juhlin R, et al. The European Spondylarthropathy Study Group preliminary criteria for the classification of spondylarthropathy. Arthritis Rheum 1991;34:1218-27.

23. Amor B, Dougados M, Mijiyawa M. [Criteria of the classification of spondylarthropathies]. Rev Rhum Mal Osteoartic 1990;57:85-9.

24. Chung HY, Machado P, van der Heijde D, et al. HLA-B27 positive patients differ from HLA-B27 negative patients in clinical presentation and imaging: results from the DESIR cohort of patients with recent onset axial spondyloarthritis. Ann Rheum Dis 2011:70:1930-36.

25. Garrett S, Jenkinson T, Kennedy LG, et al. A new approach to defining disease status in ankylosing spondylitis: the Bath Ankylosing Spondylitis Disease Activity Index. J Rheumatol 1994;21:2286-91.

26. Lukas C, Landewé R, Sieper J, et al. Development of an ASAS-endorsed disease activity score (ASDAS) in patients with ankylosing spondylitis. Ann Rheum Dis 2009;68:18-24

27. Calin A, Garrett $\mathrm{S}$, Whitelock $\mathrm{H}$, et al. A new approach to defining functional ability in ankylosing spondylitis: the development of the Bath Ankylosing Spondylitis Functional Index. J Rheumatol 1994;21:2281-5.

28. Guillemin F, Briançon S, Pourel J, et al. Long-term disability and prolonged sick leaves as outcome measurements in ankylosing spondylitis. Possible predictive factors. Arthritis Rheum 1990;33:1001-6.

29. Jones SD, Porter J, Garrett SL, et al. A new scoring system for the Bath Ankylosing Spondylitis Metrology Index (BASMI). J Rheumatol 1995;22:1609.

30. Hurst NP, Jobanputra P, Hunter M, et al. Validity of Euroqol - a generic health status instrument - in patients with rheumatoid arthritis. Economic and Health Outcomes Research Group. Br J Rheumatol 1994;33:655-62.

31. Perneger TV, Leplège A, Etter JF, et al. Validation of a French-language version of the MOS 36-Item Short Form Health Survey (SF-36) in young healthy adults. J Clin Epidemiol 1995;48:1051-60. 
32. Creemers MC, Franssen MJ, van't Hof MA, et al. Assessment of outcome in ankylosing spondylitis: an extended radiographic scoring system. Ann Rheum Dis 2005;64:127-9.

33. Strine TW, Okoro CA, Chapman DP, et al. Health-related quality of life and health risk behaviors among smokers. Am J Prev Med 2005;28:182-7.

34. Bermudez EA, Rifai N, Buring JE, et al. Relation between markers of systemic vascular inflammation and smoking in women. Am J Cardiol 2002:89:1117-19.

35. Glossop JR, Dawes PT, Mattey DL. Association between cigarette smoking and release of tumour necrosis factor alpha and its soluble receptors by peripheral blood mononuclear cells in patients with rheumatoid arthritis. Rheumatology (Oxford) 2006;45:1223-9

36. Pryor WA, Stone K, Zang LY, et al. Fractionation of aqueous cigarette tar extracts: fractions that contain the tar radical cause DNA damage. Chem Res Toxicol 1998;11:441-8.

37. Grimaldi CM, Cleary J, Dagtas AS, et al. Estrogen alters thresholds for B cell apoptosis and activation. J Clin Invest 2002;109:1625-33.

38. Shukla A, Timblin C, BeruBe K, et al. Inhaled particulate matter causes expression of nuclear factor (NF)-kappaB-related genes and oxidant-dependent NF-kappaB activation in vitro. Am J Respir Cell Mol Biol 2000;23:182-7.
39. Smith MR, Kinmonth AL, Luben RN, et al. Smoking status and differential white cell count in men and women in the EPIC-Norfolk population. Atherosclerosis 2003;169:331-7.

40. Friedman GD, Siegelaub AB, Seltzer CC, et al. Smoking habits and the leukocyte count. Arch Environ Health 1973;26:137-43.

41. Tanigawa T, Araki S, Nakata A, et al. Increase in memory (CD4+CD29+ and $\mathrm{CD} 4+\mathrm{CD} 45 \mathrm{RO}+$ ) $\mathrm{T}$ and naive (CD4+CD45RA +) T-cell subpopulations in smokers. Arch Environ Health 1998:53:378-83.

42. Sugiyama D, Nishimura K, Tamaki K, et al. Impact of smoking as a risk factor for developing rheumatoid arthritis: a meta-analysis of observational studies. Ann Rheum Dis 2010;69:70-81

43. Organisation for Economic Co-operation and Development (OECD) iLibrary. Tobacco Consumption: Percentage of Population Who Are Daily Smokers 2011. http://www.oecd-ilibrary.org/social-issues-migration-health/tobaccoconsumption_20758480-table14 (accessed 27 July 2011).

44. Jeemon P, Agarwal S, Ramakrishnan L, et al. Validation of self-reported smoking status by measuring serum cotinine levels: an Indian perspective. Nat/ Med J India 2010;23:134-6. 